\title{
Particle Design of Three-Component System for Sustained Release Using a 4-Fluid Nozzle Spray-Drying Technique
}

\author{
Richer Chen, ${ }^{a}$ Hirokazu Takahashi,${ }^{b}$ Hirokazu Okamoto, ${ }^{b}$ and Kazumi Danjo $*, b$ \\ ${ }^{a}$ Mintai Chemical Co., Ltd.; 1142, Shin Hsing Rd, Bah-Der City, Taoyuan Hsien, Taiwan, R.O.C.: and ${ }^{b}$ Faculty of \\ Pharmacy, Meijo University; 150 Yagotoyama, Tempaku-ku, Nagoya 468-8503, Japan. \\ Received April 21, 2006; accepted August 24, 2006; published online August 30, 2006
}

\begin{abstract}
We prepared composite particles of acetaminophen (Act) with chitosan (Cht) and hydroxypropylmethylcellulose phthalate (HPMCP) as a carrier using a newly developed 4-fluid nozzle spray-dryer. Cht dissolves in acid solutions and forms a gel, but it is insoluble in alkaline solutions. On the other hand, HPMCP is insoluble in acid solutions, but it dissolves in alkaline solutions. Therefore, we tested a preparation of controlled release composite particles using the characteristics of these carriers. Act and Cht mixtures in prescribed ratios were dissolved in an acid solution. Composite particles of Act and HPMCP in prescribed ratios were dissolved in alkaline solutions. We evaluated the composite particles of the three components (Act, Cht, and HPMCP) by preparing solid dispersions using a 4-fluid nozzle spray-dryer. Observation of particle morphology by scanning electron microscopy (SEM) revealed that the particles from the spray-drying process had atomized to several microns and had all become spherical. We investigated the physical properties of the composite particles by powder X-ray diffraction, differential scanning calorimetry, and dissolution rate analysis to clarify the effects of crystallinity on the dissolution rate. Powder X-ray diffraction peaks and the heat of fusion of Act in the spray-dried samples decreased in proportion to the carrier content, indicating that the drug was amorphous. These results indicate that the Act-Cht-HPMCP system formed a solid dispersion. Furthermore, we investigated the interaction between the drug and the carrier using FT-IR analysis. FT-IR spectroscopy of the Act solid dispersions suggested that the Act carbonyl and Cht amino groups formed a hydrogen bond. On the other hand, interaction by hydrogen bond was observed between the carbonyl group of HPMCP with the amino group of Act. In the three-component Act-Cht-HPMCP system, the 4-fluid nozzle spray-dried preparation with a mixing ratio of $1: 2.5: 2.5$ obtained sustained release preparation in all $\mathrm{pH}$ test solutions.
\end{abstract}

Key words acetaminophen; chitosan; hydroxypropylmethylcellulose phthalate (HPMCP); solid dispersion; sustained release

Various methods to improve the dissolution of poor watersoluble drugs have been reported. ${ }^{1,2)}$ The formation of solid dispersion using a carrier is one such method. Some researchers have proposed that increased drug dissolution rates reflect the formation of a high-energy amorphous drug phase. ${ }^{3)}$ Several water-soluble polymer carrier systems, such as polyethylene glycol (PEG), ${ }^{4-6)}$ polyvinylpyrrolidone (PVP), ${ }^{7)}$ and hydroxypropylcellulose (HPC), ${ }^{8)}$ have been used in fast-release preparations. The mechanisms of interaction between drug and carrier in solid dispersions have also been studied. Solid dispersions of nifedipine and a carrier polymer such as hydroxypropylmethylcellulose acetate succinate (HPMCAS) were prepared by a solvent method..$^{9)}$ Emara et $a{ }^{10)}{ }^{10}$ improved the dissolution of nifedipine prepared by a fusion method. Yamashita et al. ${ }^{11)}$ prepared the solid dispersion of tacrolimus using PEG, PVP, and hydroxypropylmethylcellulose (HPMC). We reported that naproxen- $\alpha$-lactose monohydrate solid dispersions, ${ }^{12,13)}$ prepared using melting methods, supported the existence of a high-energy amorphous drug phase in systems containing more than $50 \% \alpha$ lactose monohydrate. The dissolution data suggested that the dissolution rate of this phase was $7-20$-fold greater than the crystalline drug.

Recently, a spray-drying technique yielded an amorphous form of crystalline drugs, such as cimetidine, that becomes amorphous when spray-dried with Cht, as reported by He et $a l .{ }^{14)}$ This indicates that solid dispersion was formed when cimetidine was dispersed in Cht molecules by spray-drying. Corrigan et al. ${ }^{15)}$ tried to make an amorphous drug by spraydrying using PVP as a carrier. The dissolution rate of the drug commonly quickens when a solid dispersion is formed by using a polymer as a carrier. However, few studies have investigated the slow release of the drug after the formation of a solid dispersion using spray-drying. Shaikh et al. ${ }^{16)}$ performed a spray-drying technique using Act and ethylcellulose (EC) and tried to achieve a sustained release of Act. Their results demonstrated the possibility of forming solid dispersion by dispersing Act with a spray-drying technique with EC molecules in a molecular state. They concluded that the sustained release of Act in this solid dispersion was caused by an increase in EC viscosity.

In this study, we designed composite particles to the sustained release of Act by changing the mixture ratio of Act and carriers (Cht and HPMCP). Sustained release in the digestive tract was attempted in this formation by using Cht and HPMCP as carriers and solid dispersions between the carriers and drugs. Cht dissolved after it formed a gel ${ }^{17,18)}$ in the acid solution, and HPMCP was insoluble in the acid solution. However, HPMCP dissolved in the alkaline solution, and Cht was insoluble. Sustained release of the drug was tried using such dissolution properties as the $\mathrm{pH}$ of the carrier. Then the particle design of a three-component system for the sustained release of the drug was tried by forming solid dispersion using Cht and HPMCP as carriers by our 4fluid nozzle spray-drying technique. The characteristic of the 4-fluid nozzle spray-dryer are separately sent to the 4-fluid nozzle with two kinds of different solutions. The normal spray dry method can spray only one solution. 


\section{Experimental}

Materials Fijisawa Aster Co., Ltd. supplied acetaminophen (Act) as a model drug. Japan Chelate Co. Ltd. supplied a chitosan (Cht) carrier with a calculated deacetylation degree of $89 \%$ from amino group content and a coefficient of viscosity of $70 \mathrm{mPa} \cdot \mathrm{s}$. Shin-Etsu Chemical Co. Ltd. supplied hydroxypropylmethylcellulose phthalate (HPMCP) as a carrier, which is an intestine soluble coating material

Features of 4-Fluid Nozzle Spray-Dryer The 4-fluid nozzle spraydryer (Micro Mist Spray Dryer, MDL-050B, Fujisaki Electric Co., Ltd., Japan) was equipped with two gas supply routes $(0.2 \times 2.0 \mathrm{~mm})$ and two liquid-feed roads $(0.25 \times 2.0 \mathrm{~mm})$, as described in a previous paper. ${ }^{19)}$ The nozzle edge was composed of a slope that acts as a fluid flow plane, and the edge tip has a $2.0 \mathrm{~mm}$ straight section. Gas and liquid instantaneously mix by the outside mixed mode, which gathers the collision focus points at the tip of the nozzle edge. The liquid extended by the gas is atomized in the shock wave that arises from the collision focus of the edge tip. Therefore, the 4-fluid nozzle spray-dryer can spray two different solutions at once. By spraying two different solutions dissolving various substances, we can obtain composite particle of them. This is an excellent feature of the 4-fluid nozzle spray-dryer, because the 2-fluid nozzle spray-dryer can spray only single solution and it is often the case that it is hard to dissolve all the solutes in solvent.

Preparation of Physical Mixtures Physical mixtures were prepared by mixing the drug and carrier (the tested weight ratios of the drug and carrier were $1: 0.5: 0.5$ and $1: 2.5: 2.5$ ) using a test tube mixer (Scientific Industries, Vortex-Genie 2) for $10 \mathrm{~min}$ at a constant amplitude and rate. However, Act used spray-dried particles under conditions outlined in Table 1

Preparation of Composite Particles Five grammes of both Act and Cht were dissolved in the $5.0 \mathrm{ml}$ acetic acid aqueous solution, and $5.0 \mathrm{~g}$ of both Act and HPMCP were dissolved in the $24.4 \mathrm{ml}$ sodium hydroxide solution of $1.0 \mathrm{~mol}$. Both solutions were dissolved in distilled water in a total volume of $1000 \mathrm{ml}$ when the mixture ratios are $1: 0.5: 0.5$

For mixture ratios of $1: 2.5: 2.5,1.0 \mathrm{~g}$ of Act and $5.0 \mathrm{~g}$ of Cht were dissolved in a $5.0 \mathrm{ml}$ acetic acid aqueous solution, and $1.0 \mathrm{~g}$ of Act and $5.0 \mathrm{~g}$ of HPMCP were dissolved in a $24.4 \mathrm{ml}$ sodium hydroxide solution of $1.0 \mathrm{~mol}$ Both solutions were dissolved in distilled water in a total volume of $1000 \mathrm{ml}$ These solutions were separately sent to the 4-fluid nozzle, and spray-drying was carried out under the conditions shown in Table 1.

Measurement of Particle Shape and Distribution Particle shape and particle surface conditions of the sample were observed using a scanning electron microscope (SEM, JEOL Type JSM T-20, Japan). Particle size distribution of the samples was measured using laser diffraction scattering particle size distribution measurement equipment (SEISHIN ENTERPRISE, LMS-30, Japan).

Confirmation of Sample Crystallinity. Powder X-Ray Diffraction The crystallinity of the samples was measured using a vertical powder X-ray diffractometer (Rigaku Geiger-Flex diffractometer, Rad-2VC, Japan) with a Ni-filter, $\mathrm{Cu} K \alpha$ radiation, a voltage of $40 \mathrm{kV}$, and a current of $20 \mathrm{~mA}$. The scanning rate was $5^{\circ} \mathrm{C} / \mathrm{min}$ over a $2 \theta$ range of $5-45^{\circ}$.

Thermal Analysis Differential scanning calorimetry (DSC) was carried out with a DSC-60 instrument (Shimadzu Co., Ltd., Japan). Operating conditions in the open pan system included a sample weight of $10 \mathrm{mg}$ and a heating rate of $10^{\circ} \mathrm{C} / \mathrm{min}$.

Infrared Spectroscopy FT-IR spectra were obtained with a FT/IR4000 spectrometer (JASCO Corporation) using the transformations of 86 scans obtained by a $\mathrm{KBr}$ disk method.

Preparation of Model Tablets A flat-face model tablet, $50.0 \mathrm{mg}$ Act in weight and $10.0 \mathrm{~mm}$ in diameter, was prepared using a universal tension and compression tester (Shimadzu Autograph AG5000D, Japan) at a compression pressure of $62.4 \mathrm{MPa}$.

Release Tests Release tests were performed on model tablets using a JPXIV paddle method, including $50.0 \mathrm{mg}$ of the drug and $1000 \mathrm{ml}$ of the dissolution medium at $\mathrm{pH} 1.2$ or 6.8 at $37 \pm 0.5^{\circ} \mathrm{C}$. The rotation speed of the paddle was $75 \mathrm{rpm} .225 \mathrm{~nm}$ of acetaminophen was assayed by HPLC. The mobile phase was a $0.05 \mathrm{M} \mathrm{KH}_{2} \mathrm{PO}_{4}$ solution: $\mathrm{CH}_{3} \mathrm{OH}=4: 1(\mathrm{v} / \mathrm{v})$, which flowed through an ODS column (Cosmosil 5C18-AR, $4.6 \times 150 \mathrm{~mm}$, Nacalai Tesque, Japan) at $0.5 \mathrm{ml} / \mathrm{min}$.

\section{Results and Discussion}

Confirmation of Composite Particle Formation Scanning electron micrographs of the samples are shown in Fig. 1. Cht consisted of irregular shaped particles. HPMCP had
Table 1. Operating Conditions for Spray-Drying

$\begin{array}{ll}\text { Inlet temperature } & 150\left({ }^{\circ} \mathrm{C}\right) \\ \text { Outlet temperature } & 75-85\left({ }^{\circ} \mathrm{C}\right) \\ \text { Spray rate } & 10(\mathrm{ml} / \mathrm{min}) \\ \text { Blower } & 60(\mathrm{~Hz}) \\ \text { Spray air volume } & 40 \cdot 40(1 / \mathrm{min}) \\ \text { Drying air volume } & 0.8\left(\mathrm{~m}^{3} / \mathrm{min}\right)\end{array}$

(a)

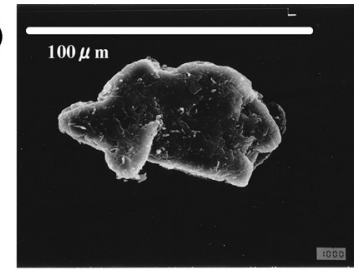

(c)

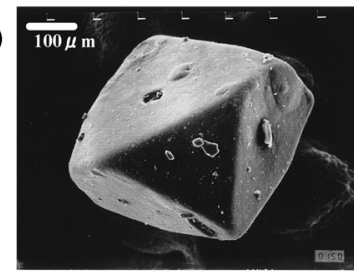

(e)

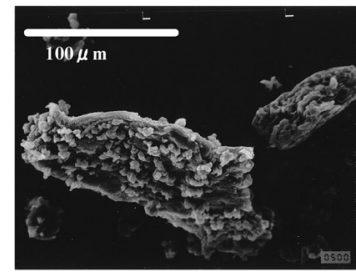

(g)

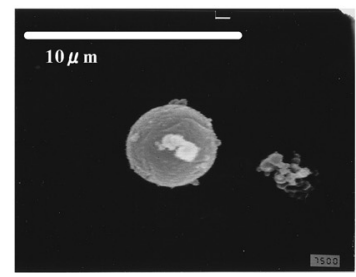

(f)

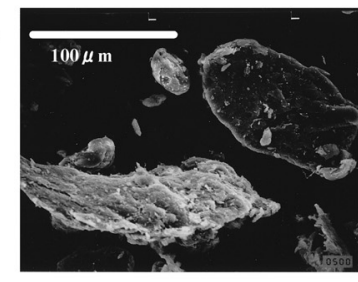

(b)

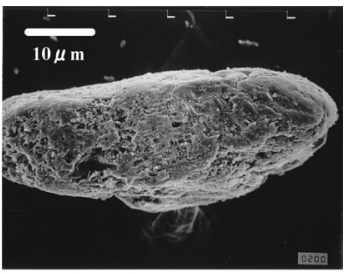

(d)

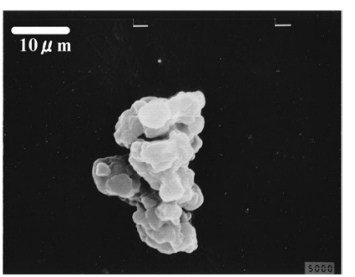

(h)

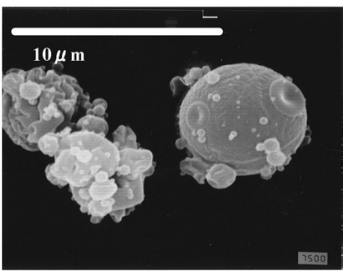

Fig. 1. SEM Photographs of Samples

(a), Cht; (b), HPMCP; (c), acetaminophen; (d), Act S.D. (e), Act: Cht: HPMCP= $1: 0.5: 0.5$ P.M.; (f), Act: Cht: HPMCP $=1: 2.5: 2.5$ P.M.; (g), Act: Cht : HPMCP= $1: 0.5: 0.5$ S.D.; (h), Act:Cht:HPMCP $=1: 2.5: 2.5$ S.D. (P.M.: physical mixture, S.D.: spray dried)

elliptical shaped particles and a pore. Act consisted of cubic shaped particles. The size of the Act S.D. particles considerably decreased in comparison with the bulk on the particle, and an aggregate was formed. However, Act particles uniformly do not adhere to the carrier particle surface like (e), when mixture ratio is $1: 2.5: 2.5$ physical mixing, because the quantity of the carrier is rich. On the other hand, spraydrying pharmaceutical preparation ( $\mathrm{g}$ and $\mathrm{h}$, as shown in Fig. 1) achieved spherical particles that became especially fine. These particle size distributions are shown in Fig. 2. Considerably large particle size was shown because Cht and HPMCP were the particle size distribution of the bulk. The mean particle size $\left(\mathrm{d}_{50}\right)$ obtained from the particle size distribution curves are shown in Table 2 . The mean particle size of 


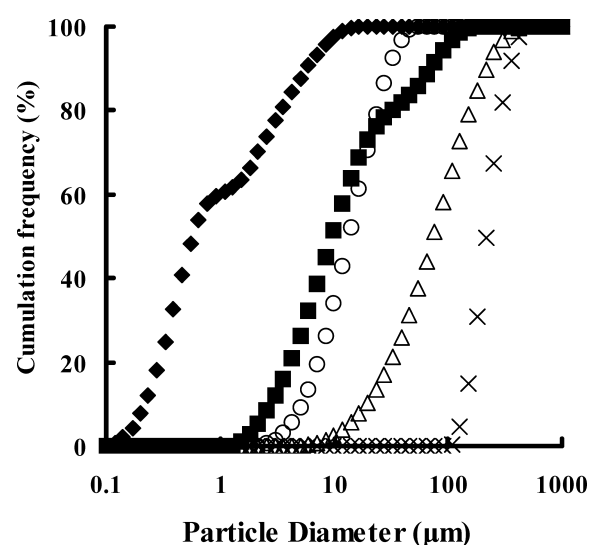

Fig. 2. Particle Size Distribution of Samples

O, Acet S.D.; $\triangle$, Cht; $\times$, HPMCP; $\mathbf{\square}$, Act: $\mathrm{Cht}: \mathrm{HPMCP}=1: 0.5: 0.5$ S.D.; Act : Cht : HPMCP $=1: 2.5: 2.5$ S.D.

Table 2. Mean Particle Size of Samples

\begin{tabular}{lc}
\hline \multicolumn{1}{c}{ Sample } & Mean particel size $(\mu \mathrm{m})$ \\
\hline Act S.D. & 13.50 \\
Cht & 75.00 \\
HPMCP & 214.69 \\
Act : Cht : HPMCP $=1: 0.5: 0.5$ S.D. & 9.57 \\
Act : Cht : HPMCP $=1: 0.25: 0.25$ S.D. & 0.58
\end{tabular}

S.D.: spray dry. $n=3$.

the spray-dried Act sample was $13.5 \mu \mathrm{m}$, which is particle size distribution in which the mixture ratio had a shoulder near $10 \mu \mathrm{m}$ on the Act:Cht:HPMCP=1:0.5:0.5 spraydried composite particles. Although mean particle size was $0.58 \mu \mathrm{m}$ on the Act:Cht: HPMCP $=1: 2.5: 2.5$ spray-dried composite particles, the mixture ratio showed particle size distribution near $1.0 \mu \mathrm{m}$ with the shoulder. That is, in this case, apparently particle size distribution for a two-component system made $1.0 \mu \mathrm{m}$ a boundary.

Confirmation of Crystallinity of Each Sample Powder X-ray diffraction patterns for Act, carriers, their physical mixtures, and the samples prepared using 4-fluid nozzle spray-drying are shown in Fig. 3. Many sharp peaks were observed in the Act diffraction patterns. Cht and HPMCP exhibited signs of amorphousness because diffraction peaks were not observed. However, in the physical mixtures, although the amplitude of the diffraction peaks decreased with an increase in the mixing ratio of carriers, we still confirmed crystallinity. On the other hand, diffractions peaks decreased, and Act's crystallinity remained on the spray-dried Act : Cht: HPMCP=1: $0.5: 0.5$ sample. However, the 4-fluid nozzle spray-dried sample at a mixing ratio of $1: 2.5: 2.5$ exhibited signs of amorphousness because diffraction peaks were not observed.

These results indicate that 4-fluid nozzle spray-dried samples with $1: 2.5: 2.5$ mixing ratios formed solid dispersions, suggesting that the drug could be dispersed homogenously in an amorphous state.

DSC measurements were carried out to confirm the composite particles suggested by the X-ray diffraction results. Figure 4 shows the DSC Act, carriers, their physical mixtures, and the samples prepared using the 4-fluid nozzle spray-drying technique. When the mixture ratio was

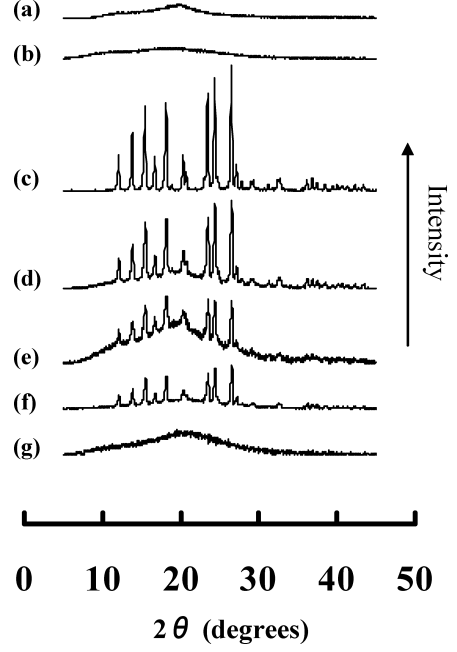

Fig. 3. Powder X-Ray Diffraction Patterns of Act-Cht-HPMCP Systems

(a), Cht; (b), HPMCP; (c), Act S.D.; (d), Act: Cht: HPMCP=1 : $0.5: 0.5$ P.M.; (e), Act: Cht : HPMCP $=1: 2.5: 2.5$ P.M.; (f), Act: Cht: HPMCP $=1: 0.5: 0.5$ S.D.; (g), Act : Cht : HPMCP $=1: 2.5: 2.5$ S.D.

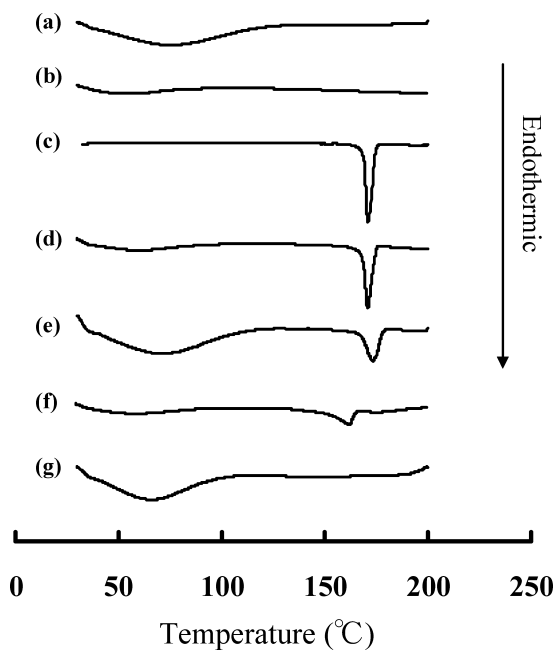

Fig. 4. DSC Thermograms of Act-Cht-HPMCP Systems

(a), Cht; (b), HPMCP; (c), Act S.D.; (d), Act: Cht: HPMCP=1 : $0.5: 0.5$ P.M.; (e), Act : Cht : HPMCP $=1: 2.5: 2.5$ P.M.; (f), Act : Cht : HPMCP $=1: 0.5: 0.5$ S.D.; (g) Act : Cht : HPMCP $=1: 2.5: 2.5$ S.D

$1: 0.5: 0.5$, an endothermic peak was slightly observed as well as X-ray diffraction measurement results, showing that in this sample it was not perfectly amorphized. On the other hand, when the mixture ratio was $1: 2.5: 2.5$, amorphization was indicated because an endothermic peak was not observed. The melting point of the samples, the heat of fusion $(\Delta H)$, and the index of crystallinity (Xc) are listed in Table 3.

The $\Delta H$ values of the physical mixture were almost identical. However, for the samples prepared using 4-fluid nozzle spray-drying at a ratio of Act: Cht: $\mathrm{HPMCP}=1: 0.5: 0.5$, $\Delta H$ values were very small, as Table 3 shows, suggesting a decrease in Act crystallinity. However, the $\Delta H$ of Act: Cht: HPMCP=1:2.5:2.5 in the 4-fluid nozzle spraydrying technique was not calculated because their samples had no endothermic peaks.

$\mathrm{X}$-Ray diffraction and DSC measurement results suggest that although Act and the carriers could not form solid dispersions with simple physical mixing, solid dispersions could be obtained when the Act:Cht:HPMCP $=1: 2.5: 2.5 \mathrm{mix}-$ 
Table 3. Melting Point (mp), Heat of Fusion $(\Delta H)$, and Crystallinity (Xc) of Samples

\begin{tabular}{lccc}
\hline \hline & $\mathrm{mp}\left({ }^{\circ} \mathrm{C}\right)$ & $\Delta H(\mathrm{~J} / \mathrm{g})$ & $\mathrm{Xc}(\%)$ \\
\hline Act (original) & 179.1 & 169.0 & 100.0 \\
Act S.D. & 168.9 & 167.7 & 99.2 \\
Act $:$ Cht $:$ HPMCP $=1: 0.5: 0.5$ P.M. & 168.9 & 158.0 & 93.5 \\
Act $:$ Cht $:$ HPMCP $=1: 2.5: 2.5$ P.M. & 167.8 & 148.5 & 87.8 \\
Act $:$ Cht $:$ HPMCP $=1: 0.5: 0.5$ S.D. & 152.1 & 37.4 & 22.1 \\
Act $:$ Cht $:$ HPMCP $=1: 2.5: 2.5$ S.D. & ND & ND & ND
\end{tabular}

P.M.: physical mixture, S.D.: spray dry, ND: peaks were not detected.

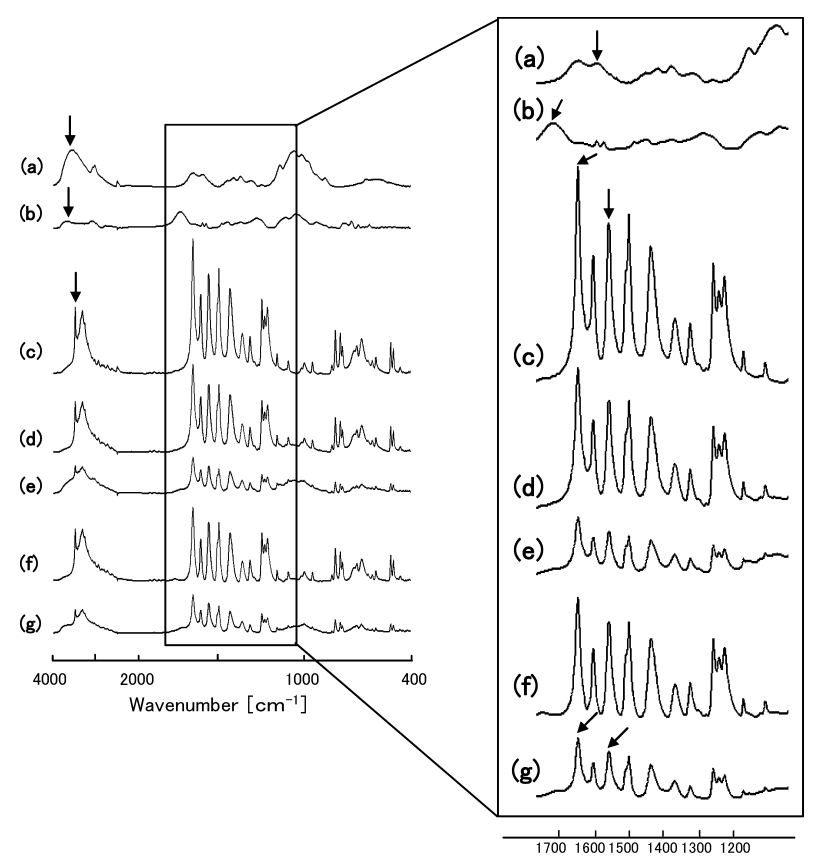

Fig. 5. FT-IR Spectra for Act-Cht-HPMCP Systems

(a), Cht; (b), HPMCP; (c), Act S.D.; (d), Act: Cht: HPMCP=1 : $0.5: 0.5$ P.M.; (e), Act : Cht : HPMCP $=1: 2.5: 2.5$ P.M.; (f), Act : Cht : HPMCP $=1: 0.5: 0.5$ S.D.; (g), Act : Cht : HPMCP $=1: 2.5: 2.5$ S.D.

tures were 4-fluid nozzle spray-dried. The degree of Act crystallinity in the solid dispersions was dependent on the ratio of drug to carrier.

Confirmation of Interaction between Act and Carriers The results of the FT-IR spectroscopy of Act, Cht, HPMCP, the physical mixture, and the spray-dried sample are shown in Fig. 5. Cht showed a broad band at $3370 \mathrm{~cm}^{-1}$ due to a stretching vibration in the hydroxyl group and a band at $1599.66 \mathrm{~cm}^{-1}$ due to an $\mathrm{NH}$ bending vibration. HPMCP showed bands at $1726.94 \mathrm{~cm}^{-1}$ due to a stretching vibration in the carbonyl group and at $3504.02 \mathrm{~cm}^{-1}$ due to a stretching vibration in the hydroxyl group. Act showed bands at $1655.59 \mathrm{~cm}^{-1}$ due to a stretching vibration in the carbonyl group, at $3325.64 \mathrm{~cm}^{-1}$ due to a stretching vibration in the amide group, and at $1565.02 \mathrm{~cm}^{-1}$ due to an $\mathrm{NH}$ bending vibration. These bands were similarly observed for the physical mixture of Act, Cht, HPMCP, and an expected band at $1726.94 \mathrm{~cm}^{-1}$ due to the carbonyl group of HPMCP, suggesting that no interaction occurred between Act and Cht in the physical mixture. The band due to the carbonyl group of stretching vibration and an $\mathrm{NH}$ bending vibration of Act in $1: 2.5: 2.5$ slightly shifted to a lower wavenumber, while the band to the amide group of Cht at $1599.66 \mathrm{~cm}^{-1}$ disappeared.

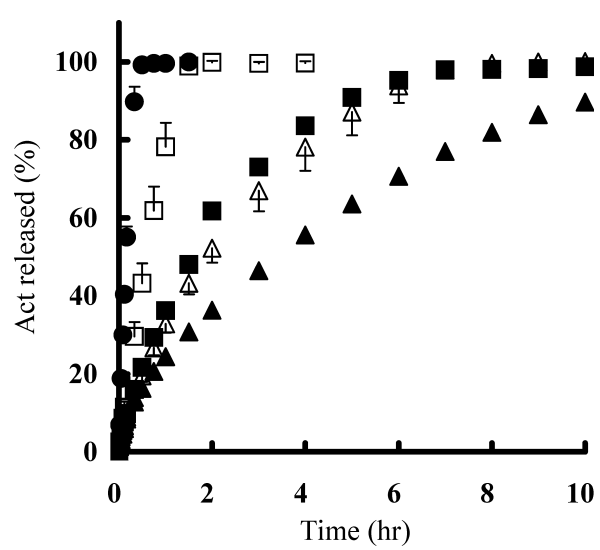

Fig. 6. Release Profiles of Act-Cht-HPMCP Systems at $\mathrm{pH} 1.2$

- Act S.D.; $\square$, Act :Cht $: \mathrm{HPMCP}=1: 0.5: 0.5$ P.M.; $\triangle$, Act $:$ Cht $: \mathrm{HPMCP}=$ $1: 2.5: 2.5$ P.M.; $\mathbf{\square}$, Act: Cht $: \mathrm{HPMCP}=1: 0.5: 0.5$ S.D.; $\boldsymbol{\Delta}$, Act $:$ Cht $: \mathrm{HPMCP}=$ $1: 2.5: 2.5$ S.D.

The band of the carbonyl group at the $1726.94 \mathrm{~cm}^{-1}$ of HPMCP was already broad in the physical mixture, and it was not observed in the spray-dried sample. These observations suggest that interaction was caused by the carbonyl group and the NH group of Act and the amide group of Cht and the carbonyl group of HPMCP.

Release Rate of Act from Composite Particles In the present study, we prepared composite particles using 4-fluid nozzle spray-drying and focused on the sustained release of Act. The relationship between the Act release from the composite particles and the interaction between the drug and carriers was examined in the following way.

The release profiles of Act from the physical mixtures and the composite particles were obtained at $\mathrm{pH} 1.2$, as shown in Fig. 6. The release in which Act S.D. was quickest is shown by zero-order. Release was dependently delayed at the carriers content in cases of physical mixture and spray-dried samples, as shown in Fig. 6. It creates a property in which HPMCP contradicts Cht for the $\mathrm{pH}$ of the solution, as described above. However, in $\mathrm{pH} \mathrm{1.2,} \mathrm{the} \mathrm{rate} \mathrm{of} \mathrm{dissolution} \mathrm{of}$ the physical mixture of $1: 2.5: 2.5$ became slower than the rate of dissolution of the spray-dried sample of $1: 0.5: 0.5$, which source in the Cht forming gel in an acidic solution, as previously described. ${ }^{19)}$ Therefore, if the amount of Cht increases, influence will appear.

On the other hand, spray-drying the pharmaceutical preparation lowers the release rate more than the physical mixture. Moreover, the release rate decreased despite amorphizing the drug because solid dispersion formed when the carrier dosage increases, which originated from $\mathrm{Cht}$ and the interaction between the drugs and the swelling effects of HPMCP.

Next we examined the release of Act from the physical mixture and composite particles in $\mathrm{pH}$ 6.8. The release profiles of the samples are shown in Fig. 7. Although the mixture ratio has almost the same release in the $1: 0.5: 0.5$ physical mixtures and spray-dried samples, when the mixture ratio is $1: 2.5: 2.5$, the release rate of the physical mixture is slightly lower. The drug release of spray-dried samples decreases with increases in the composite particles of the carrier, a result similar to $\mathrm{pH} 1.2$. The Cht property greatly affects the drug release in $\mathrm{pH}$ 6.8. That is, Cht was insoluble in the alkaline solution, lowering the drug release since Cht and Act caused the interaction. 


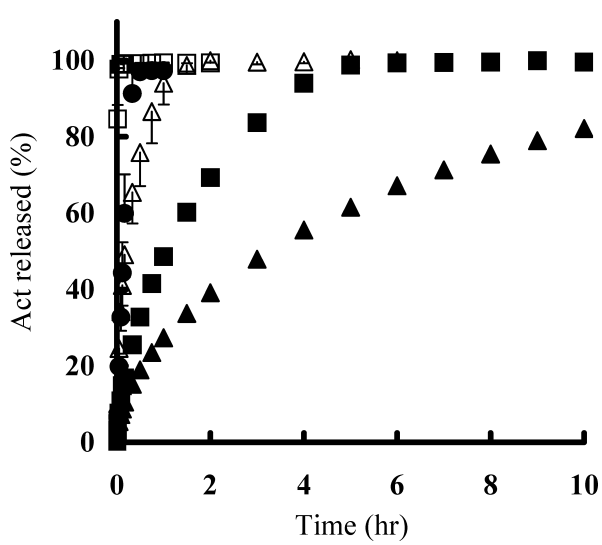

Fig. 7. Release Profiles of Act-Cht-HPMCP Systems at $\mathrm{pH} 6.8$

- Act S.D.; $\square$, Act: Cht: HPMCP $=1: 0.5: 0.5$ P.M.; $\triangle$, Act : Cht : HPMCP= $1: 2.5: 2.5$ P.M.; $\boldsymbol{\square}$, Act :Cht : HPMCP $=1: 0.5: 0.5$ S.D.; $\boldsymbol{\Delta}$, Act $:$ Cht $:$ HPMCP $=$ $1: 2.5: 2.5$ S.D.

Table 4. $\quad 70 \%$ Release Time $\left(T_{70}\right)$ of Acetaminophen

\begin{tabular}{lcc}
\hline \hline & $\begin{array}{c}T_{70} \text { at } \mathrm{pH} 1.2 \\
(\mathrm{~h})\end{array}$ & $\begin{array}{c}T_{70} \text { at } \mathrm{pH} 6.8 \\
(\mathrm{~h})\end{array}$ \\
\hline Act S.D. & 0.24 & 0.22 \\
Act $:$ Cht $: \mathrm{HPMCP}=1: 0.5: 0.5$ P.M. & 0.87 & 0.01 \\
Act : Cht : HPMCP=1 : $2.5: 2.5$ P.M. & 3.27 & 0.41 \\
Act : Cht : HPMCP=1 : $0.5: 0.5$ S.D. & 2.73 & 2.05 \\
Act : Cht : HPMCP=1 : $2.5: 2.5$ S.D. & 5.91 & 6.68
\end{tabular}

P.M.: physical mixture, S.D.: spray dry.

Based on the above drug release results, the drug release mechanism was examined. Generally, it is roughly divided into types of drug release: diffusion, matrix, and dissolution. In the present results, the spray-dried and physical mixture drugs are dissolution type. Solid dispersion is matrix type in spray-dried pharmaceutical preparations because it was formed by drug and carrier.

Therefore, the Hixson-Crowell equation is suitable, if it is the type in which particles dissolve; the Higuchi equation is suitable if it is matrix type. However, even if compared, it is pointless to obtain drug release rates using equations in which the fundamental models differ. The present testing release results should be compared in a search of $70 \%$ drug release time $T_{70}$. The $T_{70}$ of each sample at $\mathrm{pH} 1.2$ and $\mathrm{pH} 6.8$ is shown in Table 4 . The $T_{70}$ values of the $1: 2.5: 2.5$ physical mixtures became slightly larger than the $1: 0.5: 0.5$ spraydried pharmaceutical preparation in the $\mathrm{pH} 1.2$ solutions. Since solid dispersion formation is insufficient, $1: 0.5: 0.5$ spray-dried pharmaceutical preparations are regarded as a quickening of the dissolution velocity of the drug. The $T_{70}$ of the spray-dried pharmaceutical preparation of $1: 2.5: 2.5$ ratio showed about 25 times more drug delay than only spray-dried of Act. On the other hand, the $T_{70}$ in the $\mathrm{pH} 6.8$ solution greatly increased with an increase of carrier proportion, indicating a drug release delay. The value of a considerably large $T_{70}$ is shown in the spray-dried pharmaceutical preparation, which exceeded the physical mixture, and drug release delay was indicated. Spray-dried pharmaceutical preparation of $1: 2.5: 2.5$ mixture ratios showed about 30 times more drug release delay than only spray-drying of Act.

\section{Conclusion}

In our experiments, drug release control was tried by forming solid dispersion by spray-drying using the Act of a model drug with the Cht and the HPMCP of the carriers. The drug was amorphized when the mixture ratio of the carrier increased due to the formation of solid dispersion. Interaction in solid dispersion formation is caused by the carbonyl group of Act and hydrogen bonds between amino groups of Cht. However, the interaction could not be regarded as Act between HPMCP.

$1: 2.5: 2.5$ spray-dried pharmaceutical preparation, which formed solid dispersion, produced 25-30 times more sustained release than spray-dried Act.

\section{References}

1) Simonelli A. P., Mehta S. C., Higuchi W. I., J. Pharm. Sci., 58, 538549 (1969).

2) Simonelli A. P., Mehta S. C., Higuchi W. I., J. Pharm. Sci., 65, 355361 (1976).

3) Corrigan O. I., Holohan E. M., J. Pharm. Pharmacol., 36, 217-221 (1984).

4) Corrigan O. I., Holohan E. M., Reilly M. R., Drug Develop. Ind. Pharm., 11, 677-695 (1985).

5) Law S. L., Lo W. Y., Lin F. M., Chaing C. H., Int. J. Pharm., 84, 161166 (1992).

6) Mura P., Manderioli A., Bramanti G., Ceccarelli L., Drug Develop. Ind. Pharm., 22, 909-916 (1996).

7) Sekizaki H., Danjo K., Eguchi H., Yonezawa Y., Sunada H., Otsuka A., Chem. Pharm. Bull., 43, 988-993 (1995).

8) Doherty C., York P., J. Pharm. Sci., 76, 731-737 (1987).

9) Tanno F., Nishiyama Y., Kokubo H., Obara S., Drug Develop. Ind. Pharm., 30, 9-17 (2004).

10) Emara L. H., Badr R. M., Abd Elbary A., Drug Develop. Ind. Pharm., 28, 795-807 (2002).

11) Yamashita K., Nakata T., Okimoto K., Ohike A., Tokunaga Y., Ibuki R., Higaki K., Kimura T., Int. J. Pharm., 267, 79—91 (2003).

12) Hirasawa N., Danjo K., Haruna M., Otsuka A., Chem. Pharm. Bull., 46, 1027-1030 (1998)

13) Hirasawa N., Okamoto H., Danjo K., Chem. Pharm. Bull., 47, 417420 (1999).

14) He P., Davis S. S., Illum L., Int. J. Pharm., 187, 53-65 (1999).

15) Corrigan O. I., Holohan E. M., Sabra K., Int. J. Pharm., 18, 195-200 (1984).

16) Shaikh N. A., Abidi S. E., Block L. H., Drug Develop. Ind Pharm., 13, 1345-1369 (1987).

17) Hou W. M., Miyazaki S., Takada M., Komai T., Chem. Pharm. Bull., 33, 3986-3992 (1985)

18) Sawayanagi Y., Nambu N., Nagai T., Chem. Pharm. Bull., 30, 29352940 (1982).

19) Chen R., Okamoto H., Danjo K., Chem. Pharm. Bull., 54, 948-953 (2006). 